\title{
Introduction to Special Issue on 25th Anniversary of IJWIN: the First Journal Devoted to Wireless Networks
}

\author{
Kaveh Pahlavan ${ }^{1}$
}

Accepted: 21 January 2021 / Published online: 23 February 2021

(C) The Author(s), under exclusive licence to Springer Science+Business Media, LLC part of Springer Nature 2021

\section{Opening Remarks}

In early 1990s I was approached by a couple of publishers to work on the first scientific journal strictly devoted to wireless networks, because in 1991 I organized the first IEEE Workshop on Wireless Local Area Networks (WLAN), now commercially known as Wi-Fi, in Worcester, MA, and in 1992 I organized the IEEE International Symposium on Personal, Indoor, and Mobile Radio (PIMRC) in Boston, MA. I coordinated the IEEE 802.11 standardization committee meeting with the IEEE Workshop on WLAN in Worcester, MA to facilitate participation of the major industrial leaders of that time. Today, Mike Marcus, the FCC chief engineer of that time and the person in charge of release of Instrument, Scientific, and Medicine (ISM) unlicensed band, refers to that workshop as the place in which "the future of the Wi-Fi was decided" among all major players of that young industry. The 200 participants of the workshop included Chief Executive Officers (CEO's) of companies, key IEEE 802.11 standardization player, and a few professors performing related research in that area (http://www.cwins.wpi.edu/ wlans91/index.html). In 1992, in cooperation with the GTE (now Verizon) Laboratories, Waltham, MA, I organized the IEEE Personal, Indoor and Mobile Radio Communications (PIMRC) in Westin Hotel, Boston. The PIMRC symposium attracted over 500 participants with over 180 paper presentations, and a number of tutorials and panel discussion with all major figures of cellular and personal communications systems (PCS) as well as WLAN and mobile data industries (http://www.cwins.wpi.edu/workshops/PIMRC92.pdf). At this point, a need emerged for a journal to publish the results of research presented in these popular events for archiving peer-reviewed results of research. That was the reason

Kaveh Pahlavan

kaveh@wpi.edu

1 Department of Electrical and Computer Engineering, Worcester Polytechnic Institute, Worcester, MA, USA why publishers approached me to establish the International Journal of Wireless Information Networks (IJWIN).

I was lucky to attract a very distinct board of advisor, some of them still serving the journal, and the first issue of the IJWIN published in Jan 1994 with eight invited papers, the opening by Andrew J. Viterbi, the man behind the QUALCOMM Code Division Multiplexing (CDMA) technology, entitled "A Vision of the Second Century of Wireless Communications". We had three overview tutorial, lead by "Overview of GSM: Philosophy and Results, by Thomas Haug, the man behind the popular Global System for Mobile Communications (GSM) Time Division Multiple Access (TDMA) digital cellular technology of that time. This issue also had three invited technical papers by prominent names such as Donald C. Cox and Theodore S. Rappaport among the writers. Later, the journal followed this tradition and published a few pioneering inviting papers describing overview of positioning systems such as Global Positioning System (GPS) and Wi-Fi positioning technologies.

In 2019, I thought I invite a few paper for an special issue celebrating 25th anniversary (SI-25) of the IJWIN to reflect what has happened in the past few decades in the wireless networking industry. Myself and Prof. Prashant Krishnamurthy began working on the history of Wi-Fi the way we discovered its growth. Our paper is entitled "Evolution and Impact of Wi-Fi Technology and Applications: A Historical Perspective" and is the first paper of this special issue. It reviews the impact of Wi-Fi in development of wireless technologies and in our daily lives forming around the "information age". Some people believe that wireless communications is basically "applications and propagation", the first paper was a historical perspective of the most popular applications, the second paper is focused on propagation. This paper is entitles "Standardization of Propagation Models for Terrestrial Cellular Systems: A Historical Perspective" and it is prepared by Harsh Tataria, Katsuyuki Haneda, Andreas F. Molisch, Mansoor Shafi and Fredrik Tufvesson. This authoritative paper addresses evolution of RF propagation 
standards in multipath indoor and urban areas, where all wireless communications technologies operate. The third paper, entitled "An Overview on Position Location: Past, Present, Future", is written by Seyed (Reza) Zekavat, R. Michael Buehrer, Gregory D. Durgin, Lisandro Lovisolo, Zhonghai Wang, Shu Ting Goh, and Ahmad Ghasemi, and it is devoted to evolution of RF positioning technologies. It categorizes existing positioning system from a historical perspective and provide an overview of evolution of these technologies.

These three papers are now completed, and we present them in this special issue to celebrate the revolutionary growth of wireless information networking industry in the past 25 years. We hope the readers of IJWIN benefit from these papers in having and overview of evolution of wireless information networking industry and understanding of its impacts on our daily lives.

Kaveh Pahlavan,

Editor in Chief, IJWIN

WPI, Worcester, MA

Publisher's Note Springer Nature remains neutral with regard to jurisdictional claims in published maps and institutional affiliations.

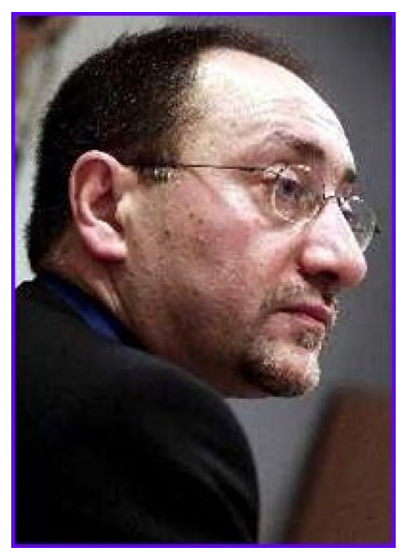

Kaveh Pahlavan is a Professor of ECE, a Professor of CS, and Director of the Center for Wireless Information Network Studies, Worcester Polytechnic Institute, Worcester, MA. Professor Pahlavan is internationally renowned as the pioneering visionary researcher of Wi-Fi Technology, Wireless IndoorGeolocation, and Body Area Networks. He has been a visiting Professor at the University of Oulu, Finland (1995-2007), where he also spent his sabbatical leave in 1999. He has spent his other sabbatical leaves at the Olin College (2004) and Harvard University (2011). Currently, he is a recipient of an "overseas famous scholar award" from R.I. China to serve as a visiting professor at University of Science and Technology Beijing (2019-2022). He has contributed to numerous seminal technical and visionary publications and patents in these areas. He is author of several pioneering textbooks, translated and taught in different languages around the world. His current area of research is opportunistic application of RF signals from wireless devices for gesture and motion detection as well as security and authentication. Prof. Pahlavan is the founding Editor-in-Chief of the International Journal of Wireless Information Networks, a member of the advisory board of the IEEE Wireless Communications Magazine since their inception in 1994. He has served as founder, co-founder or chair of several international events, including the IEEE Workshop on Wireless Local Area Networks, the IEEE PIMRC, and the IEEE International Symposium on Medical Information and Communication Technology. For his pioneering entrepreneurship activities in the growth of wireless networking industry, he has been selected as a member of the Committee on Evolution of Untethered Communication, US National Research Council (1997), and has lead the US team for the review of the Finnish National R\&D Programs in (2000 and 2003). For his contributions in research and scholarship, he was the Westin Hadden Professor of Electrical and Computer Engineering at WPI (1993-1996), was elected as a fellow of the IEEE (1996), became the first non-Finn fellow of the Nokia (1999), received the first Fulbright-Nokia fellowship (2000) and received WPI board of trustee's award for Outstanding Research and Creative Scholarship (2011). 